VOLUME 8, ISSUE 1, JanUARY 2020

DOI: https://doi.org/10.24113/ijellh.v8i1.10321

\title{
Sere life in Ashokamitran's Novel 'Water': An Eco-Critical Study
}

\author{
M. Vinothkumar \\ PhD Research Scholar \\ Department of English \\ Thiruvalluvar University \\ Serkadu, India \\ vinomv02@gmail.com
}

Dr. V. Peruvalluthi

Professor of English

Department of English

Thiruvalluvar University

Serkadu, India

A work of art defends itself with a purpose when it emerges into existence as it derives its purpose from the society out of which it comes. Water is one such work of art which is considered a masterpiece since it was published for the first time. It had been serialised in literary magazine 'Kanaiyazhi' and then published as a short novel in the year, 1973.

Ashokamitran's second novel Thanneer was translated to English with the title, 'Water' by Lakshmi Holmstrom. Ashokamitran's works are widely read and inspire young minds also because of his simple and straight language narration. His stories, characters and setting were 
derived from his life experiences. A common thing in his novels is characters who wish to involve in film industry. The author had won a number of literary awards including Sahithya kademy award in 1996 Tamilnadu government award and 'Ilakkiya Chinthanai' award. This novel 'Water' has become a classic in contemporary Tamil literary canon.

Glotfelty in the Ecocriticism Reader draws the link between nature and culture and views Ecocriticism as:

Despite the broad scope of inquiry and disparate levels of sophistication, an ecological criticism shares the fundamental premise that human culture is connected to the physical world, affecting it and affected by it. Ecocriticism takes as its subject the interconnections between nature and culture. Understanding how nature and culture constantly influence and construct each other is essential to an informed ecocriticism. As a critical stance, it has one foot in literature and the other on land. As a theoretical discourse, it negotiates between the human and the nonhuman. (109)

An ecocritic that see humans fundamentally as a part of nature will attend to representations of human cultures in all their diverse interaction with nature rather than focusing only on texts that show humans observing nature in wilderness or rural setting.

While talking of eco criticism and culture we never come across without Anbin Ainthinai, commonly known as Thinai. Sangam people were depended on nature only they praise and worship the nature. Tholkkapiyam has classified lands into five different kinds namely Kurinji, Mullai, Marutham, Neithal, Palai.

Palai, which means dry land, is the fourth type of landscape in Tamil Sangam tradition. It denotes sand and sand surrounded landscapes. However, some theorists argue that there was no such landscape in and around Tamil Nadu but 'Kurinji' and 'Mullai' thinai deviate from their natural being and transforms into Palai during summer and drought. 
Sangam literature portrays Palai thinai's primary season is summer and primary time is noon. The main themes in Palai are; food- rye, occupation- robbery, people or inhabitants- Eyinar, maravar and kalvar flowers- Patirippu and kongam pu, God- Kotravai. Their settlements were known as kurumpu. It is primarily a wasteland, unfit for living, surviving in Palai is really a hard task. Poems classified under Palai are characterised with separation and separated griefs. There is a tree named Palai which is identified as Wrightia.

Palai in modern era takes a different dimension as it no longer relies on longer poetry like it did in Sangam literature. Modern novels knowingly or unknowingly, directly or indirectly employ the Thinai tradition in them with the same intention as of Sangam poetry, that is to depict the life of people in accordance with their environment and livelihood. Some novelists in modern Tamil literature tried to portray the traits of Palai in their novels such as Poomani in his 'Vekkai', S. Ramakrishnan in his 'Nedungurudhi', and Vairamuthu in his 'Kallikkattu Idhigasam'. Modern writers do not follow the complete characteristics of Sangam landscape but they struggle to create a connectivity, a tradition between the Sangam landscape and the persisting environment.

Nedungurudhi narrates the story of a 'Kallar' village who had been living by robbery for centuries but branded as 'Kutra Parambarai' by British rulers and deviated from their original way of life Kallikattu Idhigasam tells the story of a farmer who struggled with agriculture till his death, common themes among these novels connect these novels such as seperation in relationship emptiness and failure in life, modern authors portray the life in dry land. It is quite different approach from the poetry of ancient age.

People search for water throughout the novel Water. Water acts as a force which decide their character, treatment of people and their culture these modern writers who wrote about Palai employed one significant point in their works that associates themselves with Tamil ancient poets of Palai thinai. The characters of these writes live a life in which 
livelihood will never be easy. These people (other than palai) get easily. With the focus on them, they cannot steal ox involve in robbery (as in Nedungurudhi) with the dry land waste land they cannot do farming (as in Kallikattu Idhigasam), and they have to walk search and find sources for food and water (as in Water).

Water plays a major role in Ashokamitran novel Water. There is no water in wells, corporation who is responsible for the well fare of people does not provide water. Without rain for years, the groundwater is completely gone day. people search for water; they travel long distances to get water. Many species of plant and animal life are interdependent for their sustenance, growth and development. Such mutually beneficial interdependence is called symbiotic relationship. Jamuna, the protagonist of this novel lives in Chennai during 1970's where such symbiotic relationship is not possible. It is an urban civilization where inhabitants are only consumers, as such the inhabitants of palai are only the consumers and in no way, producers. During a drought, their situation becomes worse. They wait in long queue with half hope to get water. People bear insults of water pump owners. They quarrel among themselves for waterless water. Officers and corporation workers treat this middle- class people lethargically. They excavate roads and leave them behind like nothing ever happened. They link drain water pipe with drinking water pipe. People get rain water and gather it for daily use. People who quarrelled with each other, show concern on each other after the rain starts. However, the corporation water is found to be mixed with drain water, ruins the happiness of getting water.

Chennai is the setting of the novel Water or wasteland but if is also will not fit in any other thinai. Naturally this landscape will fall under Palai. Characters in this landscape struggle very much to survive. It is a land full of rocks that is not suitable to store water in underground. If monsoon fails, next summer will be water less in Chennai. Even for drinking water people have to involve in a long struggle. During 1960's Chennai underwent a long 
drought. There was no rain for years. The drought is the setting of the novel as water. The author entitled his Novel as water to illustrate the lack of it. Like a cycle, it happens every year. Chennai faces drought each summer. Government authorities failed to maintain and develop the water deposits in and around Chennai. In 2015 flood came in all the districts of Tamilnadu which depicted the failure of rulers and people in Chennai. Successing summers proved it. Bore wells are completely gone dry. This prevailing drought is portrayed by Ashokmithran is his novel.

'Jamuna' is the main character of the novel, Water by Ashokmithran. True to life is creamery characteristic of Ashokmithran's writings, whether it is either about individual life of social problems. It is marked by simple language, clear cut pictures and round characters. These characters are introduced to readers through conversations and background pictures.

The images of water play a prominent and recurrent role as a metaphor in the novel, water. It is a symbol of intuition and a reflection of human emotion. Water less life as shown in the novel given only despair to the characters. Jamuna is the name of sacred river in India the same way water in general is purification. However in reality the river is exploited, the life of Jamuna is ruined and water in daily life is misused. 'Water' is the realistic reflection of Chennai.

Nature as an economic product is a significant argument of Rueckert. Ashokamitran showed water as an economic product in his novel. Water for daily usage is being sold by people in his novel. Rueckert argued that natural resources should be given priority for its economic products and should be paid in return. Instead, man takes natural elements as his own and makes perfect out of it. It is visible through the novel 'water'.

Parallelism as a literary device refers to repetition of words, phrases, clauses and sentences that have the same grammatical structure. In the novel 'Water' same descriptions about water come again and again. Each and every chapter project the scene of going for 
water and quarrelling for water. Two plots- Jamuna story and water in Chennai- travels hand in hand novel water. It signifies that Ecology is as important as the protagonist. Both the plots share same themes and images. At the end of the novel, both plots give same conclusion- no matter how the Sparrow is; there is still hope for life.

They cannot cultivate native plants of their region (apparently not any plans at all) they cannot ensure sustainability in harmony with nature These positively is never possible with the ecoregion of Ashokamithran's novel 'Water' which connects this ecoregion with palai thinai. Everything is lacking in Palai thinai that eventually leads people to strive hard for more existence. Without any animalistic instincts or cruelty like Bhaskar Rao, surviving is nearly impossible in that dry land. But women like Chaya, Jamuna and teacher amma across the difficult phase just with simple love and kindness. Jamuna, named after one of the three sacred rivers of India, is pointless, invisible, isolated individual who struggle under multi levels of oppression namely Caste, Class, Gender and discrimination. She always finds an emptiness around her because she is the standpoint of change between tradition and modernity.

Name of Jamuna, the environment she lives in and the incident happening at the end of the novel (mixing of drain water in drinking water) creates an irony. The author demonstrates the dangers come after ignoring the natural resources. Rivers in Chennai serve only as drain passages Rivers, Lakes and Ponds in around. Chennai are drastically affected with pollution which affects fish and other aquatic organisms. With such drought, wells go completely dry. Not only Chennai, the entire state has witnessed a number of instrumental calamities after Industrial Revolution. Neither government authorities nor common people forget to (or unaware of) take the necessary steps to avoid scarcity of water or flood during monsoon. 


\section{References}

Mitran, Ashoka. Water. Chennai: Kalachuvadu Publications, 2017. Print.

Kesigan, Puliyur. Tholkappiyam (Ezhuthu-Sol-Porul). Saradha Pathippagam, 2016.

Glotfelty, Cheryll, and Harold Fromm. The Eco criticism Reader: Landmarks in Literary Ecology. U of Georgia P, 1996. 